\title{
Unique Contributions of Churches and Clergy to Community Mental Health
}

\author{
Kenneth C. Haugk, Ph.D.*
}

\begin{abstract}
Good principles and practices of community mental health have been demonstrated by religious communities and leaders within these communities for many years. Using Caplan's model of primary-secondary-tertiary prevention, this paper articulates the unique and cooperative contributions of present-day religious institutions and personnel to the total community mental health endeavor. The validity of church's and clergy's involvement is supported by research data and is consistent with the social-psychological models of conceptualizing emotional problems. Consultation from mental health professionals can aid churches and clergy to actualize even more fully their contributions to community mental health.
\end{abstract}

Throughout most of recorded history, community mental health activities have been carried on by religious institutions and individuals within religious communities (Clebsch \& Jaekle, 1964; Frank, 1973; McNeill, 1951). Although mental health professionals have come to be regarded as those members of society whose function is to help individuals with psychological problems, they are relatively new to the role. For thousands of years, priests, witch doctors, oracles, shamans, ministers, and so on, have helped people with "problems in living" (Szasz, 1960, 1961).

As mental health professionals assumed the role of psychotherapist, the methods used became increasingly more individually oriented and less community oriented. Recently the pendulum has begun to swing back to the community. A "bold new approach" (Kennedy, 1963) within mental health has emerged which emphasizes not only treatment, but also prevention and rehabilitation. Some of the main tenets of this community mental health approach are community involvement and community control, continuity of concern, reaching those who need help the most, emphasis on services for children, planning for problem groups that nobody wants, utilization of other than mental health professionals, and consultative, educational, and preventive services to the community (Smith \& Hobbs, 1966). Community mental health center programs have been severely criticized for not carrying out the above ideals. In the first part of the Ralph Nader study on the National Institute of Mental Health, Chu and Trotter (1972) have accused community mental health centers of not following through with the intended innovations to treat and prevent emotional disturbance, but rather continuing to employ conventional and traditional approaches to mental

${ }^{*}$ Dr. Haugk, a clinical psychologist and clergyman, is Director of Pastoral Care Team Ministries, 7120 Lindell Bullivard, St. Louis, Missouri 63130. He also teaches part time at Concordia Seminary in Exile and Washington University in St. Louis. The author wishes to thank Dr. Darwin Door now at Duke University for his critical comments. 
health with only the setting different. Unfortunately, many of the criticisms of these and other investigators do have some validity.

One of the ways in which community mental health can move toward being consistent with its original goals is by working closer with clergy and churches in the delivery of mental health services to the community. Clinebell (1970) says that "Churches and temples collectively represent a sleeping giant, a huge potential of barely tapped resources for fostering positive mental health" (p. 46). Involving pastors and congregations supports one of the basic premises of community mental health, that is, increasing the number of persons who receive help for their problems. There are 393,826 ordained clergymen of all faiths in the United States including 235,189 affiliated with congregations. There are 328,657 separate congregations with an inclusive membership of $115,442,829$ (Jacquet, 1972). Both clergy and churches are geographically well located and distributed. Pastors do not charge fees, have a personal relationship with many of their parishioners, and, perhaps most important, there is relatively little stigma associated with talking to them about life problems. Moreover, the pastor does not have to wait for people to come to him. He is expected to call on persons. As well as performing various services himself, the pastor can serve as a bridge between the mental health resources of the community and members of his parish.

Since much of the mental health effectiveness of the minister is associated with the local congregation and vice versa, this paper will deal with the contributions of both of them together. The format will follow Caplan's (1964) model of primary-secondary-tertiary prevention. Primary prevention means lowering the rate of mental disorder by counteracting harmful circumstances and by promoting beneficial conditions in the environment; secondary prevention means shortening the duration of existing cases of emotional disturbance by early diagnosis and effective treatment; tertiary prevention means reducing the rate of residual defect that can continue after the mental disorder has ended. Although a clear distinction cannot always be made between the three levels of prevention, this model will serve as a general means of organization.

The main question to which this paper addresses itself is: Are there contributions to community mental health that the clergyman as a professional and that the local congregation as an institution can make that other professionals and other institutions cannot make?

\section{PRIMARY PREVENTION}

Although the most obvious mental health resource of the church is its clergymen, the local congregation as a therapeutic community contains many opportunities in which treatment and prevention can take place. The local church can be a fellowship in which love, acceptance, warmth, and understanding are in existence. Wicker and Mehler (1971) found that new members of a small church reported greater assimilation 
than new members of a large church. Thus with regard to religious communities in particular, size may be an important variable that determines the potential for group cohesiveness. Gurin, Veroff, and Feld (1960) found that proportionately more people from small towns and cities used the clergy as a resource for help with personal problems than did individuals from both rural areas and large cities. In smaller towns and cities the pastor may be perceived as a more intimate member of the community and the church as more of a community institution than in rural and metropolitan areas.

Churches can aid in reducing the psychological distances in society. Because of increasing mobility and the fast pace of life, the benefits of the traditional extended family and the community as family have been reduced. In serving as a type of extended family the local church can contribute to the reduction of "future shock" (Toffler, 1970). A minister is often the first person to visit those who have recently moved to a new community, thus making immediately available to a person or family a network of relationships as well as significant group experiences. In a study of storefront churches in a metropolitan area, Sata, Perry, and Cameron (1970) found that the churches under study frequently served as a means by which persons were helped to adjust to the larger culture of the city. Because a given church community usually is made up of individuals who are culturally and ideologically similar, the process of inclusion can be speeded up.

Each church usually has a number of large and small groups going on at any given time. Homans (1950) mentioned that early Christianity spread through its "network of new and tough groups" (p. 458) which provided meaning and belongingness for individuals. Groups within a church can be designed for people of all ages and oriented toward a variety of different issues and activities. "Emotional inoculation" (Caplan, 1964) groups can help to prepare individuals for marriage, parenthood, going to college, retirement, one's own dying, and so on. Groups can also be conducted for those who are exposed to particular life stresses that make them particularly vulnerable, for example, groups for adolescents, parents of retarded children, the recently widowed, the physically or emotionally handicapped, and unwed mothers. Mental health professionals could be secured to run some of the groups or to consult with those who are leading them.

Few institutions occupy such an advantageous position in the community for mental health education. Churches can arrange for lectures, discussions, series of classes, workshops, retreats, and the use of mass communication to enlighten and educate people about mental health. Such educational programs can disseminate cognitive information as well as deal with attitudes and feelings. Realistically, it is difficult for a community mental health center working alone to conduct mental health education programs for its catchment area. However, community mental health centers can work with churches in providing mental health education to the community. With such an arrangement, the strengths of both secular community mental health and church programs can be combined. 
In addition to providing services himself the parish pastor is an enabler of the laymen in his congregation. Here the pastor acts as a community mental health consultant - in the spirit of the community mental health movement. Laymen can serve as individual support figures and as members of "pastoral care teams," organize and lead groups, participate in "grief teams," and so on. Silverman (1969) reported on a project in which widows served as caregivers to other women whose husbands had recently died. The widowtherapists were able to establish relationships with 64 out of the 91 recently widowed clients, a high participation rate. Half were seen in person and half were talked to, at great length, on the telephone. A program similar to this could be initiated within an individual congregation or in combination with other churches or agencies.

Mention will be made of the pastor's role in crisis intervention in this section even though this activity at times may also fall under secondary and tertiary prevention. The pastor is in a unique position to do crisis intervention because of the many advantages built into his position. He is closely and continually in contact with individual parishioners and families during many of their developmental and accidental crises of life, especially those involving grief (Lindemann, 1944). He is often the first person who is contacted when a crisis occurs, and even when not approached, he still has the option of initiating relationships with persons whom he feels might benefit from some type of intervention. Switzer (1970) sums it up concisely when he says that crisis intervention is "appropriate both to his (the pastor's) historic role, the types of problems with which he is confronted, and the time which is available to him" (p. 30).

It is uncommon when a mental health professional or agency is contacted by a person at a time when intervention would be the most beneficial. Through the pastor, however, the mental health professional can have a ready access to some individuals during their crises. It is therefore important for mental health professionals to have ongoing relationships with such "firing line professionals" (Daniels, 1966).

\section{SECONDARY PREVENTION}

Although the minister makes a significant contribution to treatment, his most unique contribution within secondary prevention lies in the area of early detection and case finding. Schofield (1964) talks about the "countable thousands" who are receiving treatment and the "hidden millions" who should be but are not. The latter are those individuals who need help but do not ask for it because they are too embarrassed, or are unable to communicate with the mental health delivery system. People will not necessarily use mental health services just because they are available. This is especially true for new programs and with persons from lower socioeconomic levels. There must be individuals located within the community who are able to bridge the gap and put the client in touch with the mental health delivery system as well as bringing the system to persons in 
their own environment. Reiff and Riessman (1965) call this individual an "expediter." Administrative changes would definitely help but human links are needed.

In the nationwide survey sponsored by the Joint Commission on Mental Illness and Health, Gurin, et al. (1960) found that $42 \%$ of the individuals who had sought professional help for a personal problem consulted clergymen, the most frequently used resource. Although he did not report exact figures, McCann (1962) found that somewhat over half of the respondents stated or implied that they would go to a clergyman for help with emotional problems if they felt that help was needed. McCann said that a clergyman has a "built-in accessibility" to persons in his community, particularly his own parishioners, and is familiar with the various ways in which they solve their problems. Robinson, DeMarche, and Wagle (1960) found that many individuals went to clergymen outside of their own congregation for help with personal problems. Therefore the local pastor is serving as a mental health resource for both his own members and those who are not members of his congregation.

The pastor as a mental health resource is used by a cross-section of the population. Both Gurin et al. (1960) and Hollingshead and Redlich (1958) found that the psychiatric professions were disproportionately preferred by those of higher education and income, whereas clergy were used about evenly by all income groups as well as all educational groups. Perhaps through the effective use of clergy, community mental health programs will be more able to serve the mental health needs of all socioeconomic levels as well as the "various difficult groups that are likely to fall between the stools of current programs" (Smith \& Hobbs, 1966, p. 505).

There are many similarities between the pastor's role within community mental health and that of the indigenous nonprofessional (Reiff \& Riessman, 1965). The pastor knows the particular style of life of those he serves and more often than not lives that style of life. He sees his clients in their natural habitat and is able to take an active part in their crises. He has relationships already established with his parishioners as well as continuing contact with them. He is expected by the community to make house calls. But the pastor is more than an indigenous nonprofessional. He actually is an indigenous professional, often possessing training in pastoral care and counseling along with the above social and cultural advantages.

Along with the physician, the minister is one of the two main potential referral sources. They are the major "gatekeepers" in the helping system. The pastor's function may not necessarily be to perform the service himself. At times he indirectly participates in the helping process by first diagnosing the problem, then providing information and temporary support, and, if necessary, helping to "sell" the service or agency. The pastor is in a unique position to pave the way for referral. A minister may often be able to convince an individual to seek treatment when a family cannot. He has both a close relationship and professional authority. Many religious people are 
afraid of mental health professionals because they feel that their religion might be assaulted. The pastor can relate to the client an agency's or therapist's lack of intent to deprive the client of his religiousity, thus putting the client more at ease while at the same time helping him to be more amenable to treatment.

The minister is available for what Clinebell (1966) calls "stopgap" counseling which can be used in the interim between the time the person contacts the pastor and when he begins treatment. Stopgap counseling is valuable in two situations: when the client for a time resists referral and when he is put on a waiting list. Even if there is no reticence on the parishioner's part, many individuals need someone to explain the functions of mental health resources and other services to them. Many individuals are not even aware of the existence of various agencies and need to be educated so that they can make use of community resources. The pastor as a community professional is already familiar with many of the community resources. However, Bentz (1967) found that although an overwhelming majority of the ministers in his study were aware of the existing mental health resources, they used them relatively little.

It would seem that an area in which clergy and community mental health centers could definitely work together for each other's mutual benefit is with regard to referral. Pastors (as well as other community caregivers) refer relatively few of the individuals whom they could refer (Cumming \& Harrington, 1963; Gurin, et al., 1960; Hollingshead \& Redlich, 1958). Bentz (1967) studied the relationship between the educational background of ministers and their role in counseling, prevention, and referral. He found that there were no educational differences in counseling and prevention but that there was a significant educational difference between them as to how much they referred, the less educated ministers referring less. This suggests that education may do much to solve this referral problem. Supporting this contention are Westberg and Draper (1966) who reported that as a result of participating in a clinical pastoral education workshop, pastors increased their ability to detect emotional disturbance and to make appropriate referrals. Piedmont (1968) found that the proportion of parishioners or patients referred by pastors or general practitioners to mental health personnel was positively correlated with the proportion of reports fed back to them by the mental health professionals. This research suggests that referrals from clergy and general practitioners might be increased by involving them in the treatment process insofar as giving them information about the client's progress.

\section{TERTIARY PREVENTION}

Since many of the general characteristics, methods, functions, and so forth, of the church and clergy's unique involvement in community mental health that could apply to tertiary prevention have already been discussed under primary and secondary prevention, this sec- 
tion will be somewhat shorter. The pastor and congregation working together can play a key role in reducing the rate of residual impairment in those whose disorder is of a very serious or chronic nature.

When an individual enters into treatment with a mental health professional or agency, the pastor can counsel concurrently with the family. This is especially relevant when the family member is receiving inpatient care. Also, in collaboration with the therapist or agency, the pastor can inform the family about what is happening in treatment. Counseling with the family may make it easier for the patient to reenter his home environment.

The local minister should be encouraged to keep in contact with the identified patient during the period of hospitalization. If possible, it is usually better for the home pastor rather than the hospital chaplain to be the patient's primary spiritual resource. The home pastor may be one of the few contacts that the person has with his original environment. While the person is away, the pastor can also encourage a caring ministry among the members of the congregational community as well as deal with attitudes and feelings that they may have about "mental illness."

In many instances there is a gap between the mental health services and the community in the care of the emotionally disturbed after treatment. Maintaining contact with a formerly institutionalized patient after discharge has been one of the main problem areas of mental health delivery. Involving the pastor in aftercare may contribute to the prevention of rehospitalization. Because of his social and geographic proximity to the client, the pastor is better able to control the follow-up contingencies than is a mental health professional or institution.

Perhaps the greatest need a patient has at the time of discharge is a need for community. When an individual is discharged, he does not need indepth psychotherapy from the community. What he needs is a stable environment that provides warmth, trust, and acceptance. In addition to providing these the local church can also offer activities and groups in which an individual can participate.

Helping to maintain the "marginal" person in society is another common tertiary prevention function of the pastor and congregation. The minister has excellent resources for supportive care with the aged, the chronically emotionally disturbed, and the chronically physically ill. Churches and clergy frequently help to maintain individuals who were originally thought to need permanent inpatient incarceration in psychiatric treatment facilities. Within the sustaining program of a church community, the individual may counsel occasionally with the pastor as well as become involved in many activities within the religious community.

\section{DISCUSSION AND CONCLUSIONS}

We have seen in this paper how both conceptualizations and empirical research validate the church and clergy's involvement in community mental health. Religious resources are able not only to duplicate 
some tasks for the mental health delivery system but to fulfill new ones. Some unique contributions are made by churches and clergy working alone. At other times a unique contribution is made to community mental health when church and mental health resources work together. Whenever two or more disciplines work together in a single task, problems in communication exist. The community mental health endeavor is no exception. Many clergymen are wary of "shrinks." At the same time many mental health personnel have negative feelings about ministers and churches. Although there are admitted deficiencies on both sides, most of the preconceptions usually turn out to be inaccurate stereotypes. One difficulty is that clergy often think that mental health professionals are all alike and vice versa. In a series of studies, Larson (1965a, 1965b, 1967, 1968) demonstrated that ministers of different denominations hold different attitudes about mental health as well as different opinions about the causes of emotional disturbance. This research demonstrated that ministers are not alike with regard to their training and psychological sophistication in the mental health area. Perhaps it would be advisable for mental health professionals to work with clergy according to their skills, attitudes, and potential for contributing to community mental health.

Bentz (1968) found that there was a difference between the actual behavior of ministers and what they thought they should be doing with regard to prevention, counseling, and referral. This research suggests that clergy may be open to education and consultation. Consultation with community caregivers is a good investment of a mental health professional's time. It is important that the clergyman keep his own professional identification if he is to continue to be uniquely effective. He can contribute far more to community mental health as a pastor than as a "junior psychiatrist."

There is no need to join with churches and clergy in the community mental health endeavor as a favor to them. Mental health needs clergy and the religious community to be true to its overall goal. Conversely, churches and temples need community mental health in order to be true to their mission of ministering to the whole person. "The enormity of developing comprehensive total care services as an objective of a community mental health program require(s) the examination and full utilization of all potential community resources" (Sata, et al., 1970, p. 256). If the churches and clergy do not make their unique contributions, the contributions probably will not be made.

\section{REFERENCES}

Bentz, W. K. The relationship between educational background and the referral role of ministers. Sociology and Social Research, 1967, 51, 199-208.

Bentz, W. K. Consensus between role expectations and role behavior among ministers. Community Mental Health Journal, 1968, 4, 301-306.

Caplan, G. Principles of preventive psychiatry. New York: Basic Books, 1964.

Chu, F., \& Trotter, S. (Eds.) The mental health complex: Community mental health centers (Part I of the NIMH Report). Washington, D.C.: Center for the Study of Responsive Law, 1972. 
Clebsch, W. A., \& Jaekle, C. R. Pastoral care in historical perspective. Englewood Cliffs, N. J.: Prentice-Hall, 1964.

Clinebell, H. J., Jr. Basic types of pastoral counseling. Nashville, Tenn.: Abingdon, 1966.

Clinebell, H. J. Jr. The local church's contribution to positive mental health. In $\mathrm{H}$. J. Clinebell (Ed.), Community mental health: The role of church and temple. Nashville, Tenn.: Abingdon, 1970.

Cumming, E., \& Harrington, C. Clergyman as counselor. American Journal of Sociology, 1963, 69, 234-243.

Daniels, R. S. Community psychiatry-A new profession, a developing subspecialty, or effective clinical psychiatry? Community Mental Health Journal, 1966, 2, 47-54.

Frank, J. D. Persuasion and healing: A comparative study of psychotherapy (2nd ed.). Baltimore, Md.: Johns Hopkins Press, 1973.

Gurin, G., Veroff, J., \& Feld, S. Americans view their mental health: A nationwide interview survey. New York: Basic Books, 1960.

Hollingshead, A. B., \& Redlich, F. C. Social class and mental illness: A community study. New York: Wiley, 1958.

Homans, G, C. The human group. New York: Harcourt, Brace and Company, 1950.

Jacquet, C. H., Jr. (Ed.). Yearbook of American churches 1972. Nashville, Tenn.: Abingdon, 1972.

Kennedy, J. F. Message from the President of the United States relative to mental illness and mental retardation. February 5, 1963, 88th Congress, First Session, House of Representatives, Document No. 58.

Larson, R. F. Attitudes and opinions of clergymen about mental health and causes of mental illness. Mental Hygiene, 1965, 49, 52-59. (a)

Larson, R. F. Psychiatric orientations of a selected sample of New England clergy. Mental Hygiene, 1965, 49, 341-346. (b)

Larson, R. F. Denominational variations in clergymen's attitudes concerning mental health. Mental Hygiene, 1967, 51, 185-191.

Larson, R. F. The clergyman's role in the therapeutic process: Disagreement between clergymen and psychiatrists. Psychiatry, 1968, 31, 250-263.

Lindemann, E. Symptomatology and management of acute grief. American Journal of Psychiatry, 1944, 101, 141-148.

McCann, R. V. The churches and mental health. New York: Basic Books, 1962.

McNeill, J. T. A history of the cure of souls. New York: Harper \& Row, 1951.

Piedmont, E. B. Referrals and reciprocity: Psychiatrists, general practitioners, and clergymen. Journal of Health and Social Behavior, 1968, 9, $29-41$.

Reiff, R., \& Riessman, F. The indigenous nonprofessional. Community Mental Health Journal, 1965, Monograph No. 1.

Robinson, R., DeMarche, D. F., \& Wagle, M. Community resources in mental health. New York: Basic Books, 1960.

Sata, L. S., Perry, D. A., \& Cameron, C. E. Store-front churches in the inner city. Mental Hygiene, 1970, 54, 256-260.

Schofield, W. Psychotherapy: The purchase of friendship. Englewood Cliffs, N. J.: Prentice-Hall, 1964.

Silverman, P. R. The widow-to-widow program: An experiment in preventive intervention. Mental Hygiene, 1969, 53, 333-337.

Smith, M. B., \& Hobbs, N. The community and the community mental health center. American Psychologist, 1966, 21, 499-509.

Switzer, D. K. Crisis intervention techniques for the minister. Pastoral Psychology, 1970, 21(203), 29-36.

Szasz, T. S. The myth of mental illness. American Psychologist, 1960, 15, 113-118.

Szasz, T. S. The myth of mental illness: Foundations of a theory of personal conduct. New York: Hoeber-Harper, 1961.

Toffler, A. Future shock. New York: Random House, 1970.

Westberg, G. E., \& Draper, E. Community psychiatry and the clergyman. Springfield, Ill.: Charles C Thomas, 1966.

Wicker, A. W., \& Mehler, A. Assimilation of new members in a large and small church. Journal of Applied Psychology, 1971, 55, 151-156. 